\title{
Research on Project Management and Operation of Aerospace Technology Application Industry in the New Era
}

\author{
Hairu Li ${ }^{1, a}$ and Zhenzhong Ma1,b \\ ${ }^{1}$ Fluid and Rotating Machinery Division, Beijing Aerospace Propulsion Institute, China \\ alihr2@calt11.cn, bmazhzh@calt11.cn
}

Keywords: Project management, Aerospace technology, Related interest.

\begin{abstract}
In today's society, the project is a strategic carrier to realize enterprise development, and project management is a strategic measure for enterprise development. Corresponding author is optional. This paper discusses the three-coordinate management system of project management through the description of the importance and necessity of project management, and analyzes the operation of project management in the aerospace technology application industry project. Through the project management mode, the aerospace technology application industry project will realize cost control, schedule guarantee and performance improvement, and lay the foundation for the development of the aerospace technology application industry to a higher level.
\end{abstract}

\section{新时代下航天技术应用产业项目管理运行研究 \\ 李海茹1,a, 马振中1,b \\ 1 北京航天动力研究所流体与旋转机械事业部, 北京, 中国 alihr2@calt11.cn, bmazhzh@calt11.cn}

关键词：项目管理；航天技术；利益相关

中文摘要. 在当今社会中, 项目是实现企业发展的战略载体, 项目管理是企业发展的战略措 施。本文通过对项目管理的重要性和必要性的描述，讨论了项目管理的三坐标管理体系，并 将项目管理在航天技术应用产业项目中的运行进行了分析。通过项目管理模式，使航天技术 应用产业项目实现成本控制、进度保证、性能提升，奠定航天技术应用产业向更高层次的发 展的基础。

\section{1. 引言}

“商界教皇”Tom Peters指出：项目管理是成功的关键，“管理之父”David Cleland认为：项 目管理在全球性的市场变化中起着关键作用，由此可见项目管理的重要性。项目管理就是以 项目为对象的系统管理方法, 通过一个临时性的、专门的柔性组织, 对项目进行高效率的计 划、组织、指导和控制, 以实现项目全过程的动态管理和项目目标的综合协调与优化 ${ }^{[1-3]}$ 。

对于航天技术应用产业运行项目来说，某航天公司自提出项目管理理念以来，已成功运 作了几百项国内大项目，同俄罗斯、日本、韩国、中东、孟加拉等国家合作过几十项国际化 项目，之所以取得如此可观的成绩，很大程度上得益于项目管理的支撑和保障。 


\section{2. 项目管理的三坐标管理体系}

项目管理的组织通常是临时性、柔性、扁平化的组织，项目管理的机制是项目经理负责 制，项目管理的方式是目标管理，包括进度、费用、性能，项目管理的宗旨是创造和保持一 种使项目顺利进行的良好氛围 ${ }^{[4]}$ 。如图1所示，项目管理的范围从以下图可以清楚地看出。

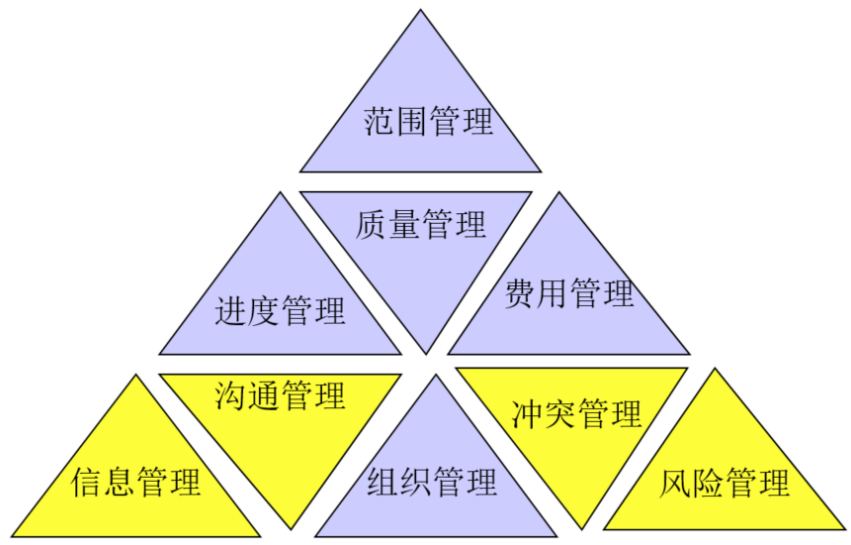

图1 项目管理范围

图1为项目管理范围，从中可以看出项目管理的三坐标管理体系。进度管理是项目能否按 期实现的基本保证; 费用管理是对实现项目所需要的经费进行合理有效的管理，使得项目的 费用支出与进度相协调; 质量管理是使所实施的项目达到设计质量及技术指标的关键，是项 目得以顺利完成的基础。

进度、费用与质量是项目管理过程中最重要的三个变量, 他们之间在项目的实施过程中 有一个平衡问题 ${ }^{[5,6]}$ 。如何在航天技术应用产业项目的实施过程中有效的使项目的进度、费用 与质量相互匹配、相互协调，就构成了项目管理的三坐标管理体系。

\section{3. 项目管理在产业项目中的运行分析}

近几年来，某航天公司依托航天火箭动力专业技术优势，建立了一整套的项目管理体系、 项目管理流程、项目管理标准，为我国能源煤化工等行业提供了大量的化工设备。所有这些 项目的成功开展都离不开项目管理的支撑。

(1) 项目经理制

项目经理是项目管理的直接责任人，项目经理按合同规定的供货范围、内容和约定的交 付工期、质量标准、合同价格，制定具体的项目目标和技术方案、监督生产进度，及时向公 司领导汇报项目进度、费用控制及工程存在的阶段性问题，保持与业主的信息交流和协作， 明确业主需求，保证业主满意。

(2) 强化核心技术

强化核心技术, 抓好重点项目和重点产品, 为以后项目的开展积累经验, 突出结构设计 等核心技术特点，向客户展现公司航天高科技含量，高附加值的技术产品，满足项目管理三 大要素最重要的 “性能” 要求, 为客户提供最满意的交付物。

(3) 运用合理组织模式

矩阵式组织结构适用于技术复杂、规模大、多部门协调的项目，所以针对多个项目同时 开展的情况, 项目管理采用矩阵式组织模式。这种组织模式不但节约了人力资源, 降低了成 本，而且保证了员工与企业同步成长。

(4) 挣得值分析法

通常为了对项目进度和费用进行综合度量和控制，采用挣得值分析方法来标示项目进展 状态，其中费用偏差和进度偏差计算公式分别如式（1）和（2）所示。 


$$
\begin{aligned}
& C V=B C W P-A C W P \\
& S V=B C W P-B C W S
\end{aligned}
$$

其中, 费用偏差公式中的 $C V$ 为正值时表示费用节省, 反之不然; 进度偏差公式中的 $S V$ 为正值时表示进度提前，反之不然。

对某航天公司 27 个项目的出厂里程碑关键点进行抽样调查, 其中 27 个项目 $C V$ 均为正值, 标明费用没有超标; 其中 25 个项目 $S V$ 为正值, 表明进度提前, 另外 2 个项目因用户现场不具 备进场条件而滞后, 所以 $S V$ 为负值。

（5）项目管理流程化管理

公司建立了一整套项目管理流程，包括合同签订、备件采购、发货管理、现场管理等等， 所有这些流程为项目顺利执行提供了规范化和标准化, 有力地控制了成本和时间, 提高了项 目执行效率。

（6）项目管理具体实效分析

包括：(1)项目管理性能方面：最为典型的是国际化项目，由于其高效的反馈机制和产品 的高性能得到了用户的肯定和满意，满足国际用户的各种技术性能要求，使项目利益相关者 都获益。(2)项目管理进度方面：对于业主要求交付时间短的项目，项目团队合理调配和优化 资源，仅用了 2 个月的时间，就及时准确地完成了交付，保证了合同的履行，也为后续合作提 供现实依据。(3)项目管理成本方面：每个项目经理都清楚本项目的成本构成，保证每一个环 节的预算不超标。通过项目管理的良好运用，带来了 $3 \sim 4 \%$ 的成本控制效益，为公司开展其 他项目节约了资金。(4项目管理的优良运作直接获得订单。项目管理的成功运营使公司在进 度、性能、成本等方面都取得了优异成绩，取得了客户的信任和认可，为后期项目直接合作 奠定基础。

\section{4. 产品项目实施的四个阶段分析}

航天技术应用产业项目管理，是一个非常复杂的过程，下面以航天泵类产品为例，讨论 项目管理的具体应用。

(1) 项目启动阶段

在合同签订后, 就要与业主沟通, 明确用户对 “三要素” 的需求, 在编制项目计划时, 应通过项目三坐标的反复平衡, 求得最佳的经济效果, 提出技术方案和项目建议书, 制定项 目产品流程图。

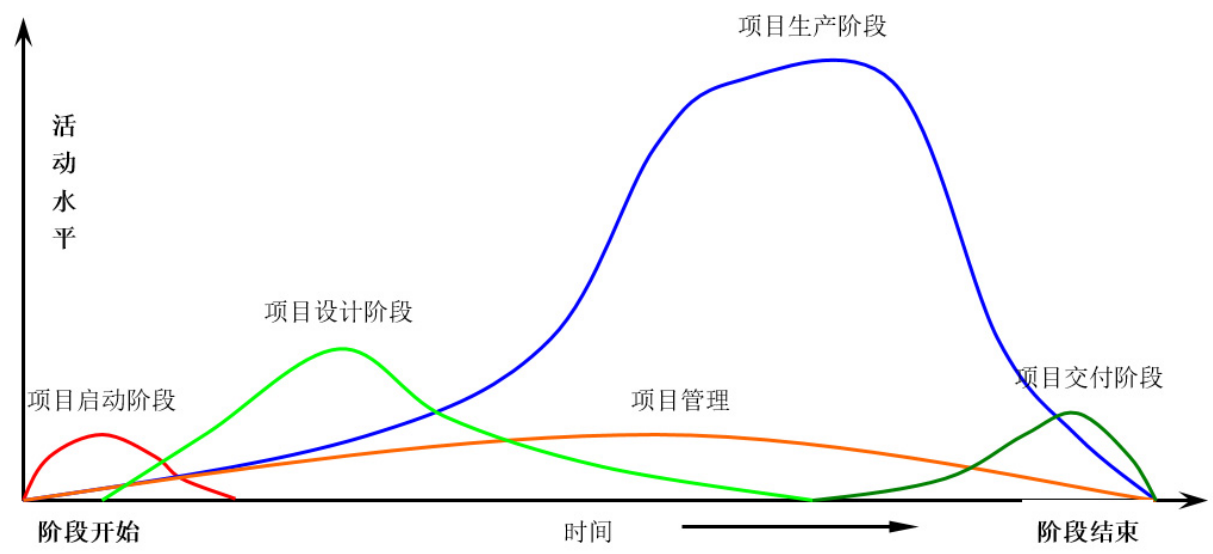

图2 项目实施的不同阶段 
(2) 项目设计阶段

项目设计阶段, 建立矩阵组织模式, 在开工会上和方案评审会上明确项目的供货范围, 确定技术实施方案, 然后各专业组之间进行设计参数的交接, 列出项目的工作结构分解

（WBS），制定相应的项目实施制度，确保项目执行的有效性。

(3) 项目生产阶段

生产阶段, 首先要建立完善的项目信息和沟通渠道, 保证信息畅通、沟通有效, 同时对 生产过程进行过程监控，最后对整机进行出厂试验，确认随机资料、产品质量证明文件的完 整，保证项目的质量、成本、进度按既定目标完成。

(4) 项目交付阶段

进入产品的安装调试交付阶段，设备运输到用户现场，进行现场开箱、验收，安装和调 试, 提交竣工图和用户验收报告。成功完成开车运行后, 进入设备的售后服务中。图2为项目 实施过程的不同阶段示意图。

\section{5. 航天技术项目管理讨论}

航天技术应用产业项目具备了项目的特性，在项目执行过程中因客户需求的个性化及外 协生产方式的变化，给项目的执行带来了复杂性。(1)项目经理要同时管理多个项目，因此项 目经理的选择非常重要, 必须具备丰富的项目管理经验、专业技术能力和团队合作精神, 能 有效分配人力、物力等资源，能带领项目团队同心协力地完成既定目标，达到公司效益最大 化。(2)根据项目的特征, 及时调整组织结构, 采用矩阵式项目组织模式, 提高对外部环境的 应变能力。在项目设计阶段, 就要做到顶层优化设计、降低成本。(3)在项目执行中总结项目 管理的成果, 引进项目管理成熟度模型, 为组织项目管理的应用提供一套可供衡量的标准, 越高的成熟度，性能、进度、成本越容易控制。(4)要实现性能、进度、成本控制得到项目利 益相关者的满意, 实现项目的最终目标, 要善于运用可视化图表工具, 确保项目三要素的整 体平衡，确保项目既定目标的圆满实现。

\section{6. 结束语}

通过项目管理模式，运用项目管理的知识和技术,使航天技术应用产业项目运行从过去的 自发、自觉、自然的状态转变到规范化、制度化、系统化的体系中, 形成了全员参与的项目 管理文化，为航天技术应用产业向更高层次的发展打下了坚实的基础，为公司的发展起到 “助 推器” 的作用。

\section{References}

[1] A. Lester, Project planning and control, Journal of the Operational Research Society, vol. 34, pp. 918-918, 1983.

[2] K. G. Cooper, J. M. Lyneis, and B. J. Bryant, Learning to learn: from past to future, International Journal of Project Management, Vol. 4, pp. 213-219, 2002.

[3] H. Kerzner, and H. R. Kerzner, Project management: a systems approach to planning, scheduling, and controlling, Quality Progress, Vol. 22, pp. 37-42, 2006.

[4] J. Russell-Hodge, Total project management: The customer-led organization, International Journal of Project Management, Vol. 13, pp. 11-17, 1995.

[5] D. Partington, The project management of organizational change, International Journal of Project Management, Vol. 14, pp. 13-21, 1996. 
[6] C. F. Gomes, M. M. Yasin, and J. V. Lisboa, Project management in the context of organizational change, International Journal of Public Sector Management, Vol. 21, pp. 573-585, 2008. 